\title{
Dr R. E. Evans
}

The Editors regret to announce the death of Dr Richard Evan Evans on 17 May 1983 in Aberystwyth, at the age of 84. Dr Evans worked for the whole of his career at the School of Agriculture, Cambridge, where he was on the staff of the Animal Nutrition Research Institute as well as being actively engaged in teaching.

Evans succeeded Dr H. E. Woodman, with whom he had a long and very successful research partnership, on the Editorial Board of the Journal in 1956, and he resigned in 1965. During this period he contributed invaluable service to the Journal's operation as adviser on a wide range of topics in animal nutrition, and he refereed many papers both before and after his editorial participation. In addition, he supported the Journal over a long period through the publication of a sustained series of papers with his senior colleague, Woodman, which had considerable impact in scientific and agricultural spheres concerned with animal husbandry. 